\title{
Major Bacteria Species Surface Contaminants in Hospitals of Littoral Region, Cameroon
}

\author{
Takemegni Wandji Jonas Merlin ${ }^{1,2}$, Assob Nguedia Jules Clement ${ }^{1, ~ *}$, Ateudjieu Jérôme ${ }^{3,4,5}$, \\ Enow Orock George ${ }^{1}$, Ngowe Ngowe Marcelin ${ }^{1,6}$ \\ ${ }^{1}$ Department of Biomedical Sciences, Faculty of Health Sciences, University of Buea, Buea, Cameroon \\ ${ }^{2}$ Department of Medical Laboratory Sciences, New-Bell District Hospital, Douala, Cameroon \\ ${ }^{3}$ M. A. SANTE (Meilleur Accès aux Soins de Santé/Better Access to Health Care), Yaounde, Cameroon \\ ${ }^{4}$ Department of Biomedical Sciences, University of Dschang, Dschang, Cameroon \\ ${ }^{5}$ Division of Health Operations Research, Ministry of Public Health, Yaounde, Cameroon \\ ${ }^{6}$ Department of Clinical Sciences, Faculty of Medicine and pharmaceutical Sciences, University of Douala, Douala, Cameroon
}

Email address:

takus2@yahoo.fr (T. W. J. Merlin), juleclement@yahoo.fr (A. N. J. Clement), jateudj@yahoo.fr (A. Jeurome), enowrock24@yahoo.fr (E. O. George),nkouki2000@yahoo.fr (N. N. Marcelin)

${ }^{*}$ Corresponding author

\section{To cite this article:}

Takemegni Wandji Jonas Merlin, Assob Nguedia Jules Clement, Ateudjieu Jérôme, Enow Orock George, Ngowe Ngowe Marcelin. Major Bacteria Species Surface Contaminants in Hospitals of Littoral Region, Cameroon. European Journal of Clinical and Biomedical Sciences. Vol. 6, No. 3, 2020, pp. 26-34. doi: 10.11648/j.ejcbs.20200603.11

Received: May 19, 2020; Accepted: June 1, 2020; Published: June 16, 2020

\begin{abstract}
Globally, the levels of healthcare-associated infections (nosocomial infections) are important high, and especially those due to bacterial are significant and costly. Healthcare environments provide a worrying reservoir for spreading infections. According to the World Health Organization (WHO) Low and Middle-Income Countries may be particularly at risk, hence, the need to perform a timely assessment of surface contamination of bacterial origin in the major units of four different hospitals of the Littoral Region, Cameroon. A cross-sectional and descriptive study was conducted from December 2018 to May 2019. A simple random sampling was used to swap 10 selected equipment (treatment tables, operating tables, delivery tables, office tables, anesthesia equipment, surgical aspirators, oxygen concentrators, wheelchairs, patients and office chairs) and 10 materials (fans, patient bedside tables, patient bed rails, trolleys, door handles, negastoscopes, baby scales, air conditioners, Antiseptic container boxes, and covers) in the mornings after disinfection but before the start of work in each unit. After inoculation in four agar media consecutively (Eosine Methylene blue, Cled, Mannitol salt agar and the blood agar in segmented) and incubated in appropriate conditions, identification and confirmation were based on morphological characteristics of bacteria colonies, microscopy, and biochemical methods using API staph, strep, and $20 \mathrm{E}^{\mathrm{TM}}$ gallery Biomerieux. Of a total of 236 samples collected, $119(50.4 \%)$ showed bacterial growth, 33 different species of which 62/119 (52.10\%) were Gram-positive cocci, 57/119 (47.90\%) Gram-negative bacilli. S. aureus, 45/119 (37.81\%), E. coli 6/119 (5.04\%), and Acinetobacter spp 4/119 (3.36\%) were the most common contaminants. Patients' bedside tables, office chairs, and patients' bed rails were the highest contaminants respectively 14/119 (11.76\%), 13/119 (10.92\%) and 12/119 (10.08\%). The Emergency units were the mainly contaminated area for Gram-positive cocci, $12 / 62$ (19.35\%) majority S. aureus 9/62 (14.51\%) as most as Gram-negative non-Enterobacteriaceae 11/31 (35, 48\%) with a predominance of C. meningoseptica and M. heamolytica both $2 / 31(6.45 \%)$. Therefore for the Gram-negative bacilli Enterobacteriaceae family, the highest level of bacterial isolates was recovered in laboratory $7 / 26(26.92 \%)$, in which E. coli was predominantly reported 4/26 (15.38\%). However, S. aureus was the only species found in all hospitals and units. This high level of contamination in various key units in these hospitals is a serious risk of infections with leading to complicated and cost healthcare. This work will help clinical care and decision making to take appropriate actions to improve sanitation and ensure control measures to limit the spread of hospital-acquired infections.
\end{abstract}

Keywords: Bacteria Species, Contamination, Hospital Environment, Littoral, Cameroun 


\section{Introduction}

Nosocomial infections (NI) are referred to as any systemic or localized condition that is caused by an infectious toxin or agent from the hospital [1]. This term is used interchangeably with the term Health-care Associated Infections (HAIs) and is also now known as Hospital-Acquired Infections. HAIs are infections acquired in the hospital by patients who are admitted for other reasons than the initial cause of hospitalisation, after 48 hours or more hospital admission or within 30 days after discharge [2-3]. NI remains a public health problem worldwide with the most significant causes of morbidity and mortality in healthcare settings [4]. In developed countries, NI affects between $5 \%$ and $15 \%$ of hospitalized patients in regular wards and remains underestimated in developing countries [5]. However in Africa some studies have shown that the overall prevalence can reach $25 \%$ [4-]. It can be found anywhere medical care is given (hospital, clinic, and patient's home) [5], generally, associated to poor hygiene. Most of the microorganisms are transmitted by hands and instruments contaminated that have come into contact with patients, with body fluids [7, 8]. Modern medical care has become more invasive and therefore associated with a greater risk of infectious complications. Hospital lengths of stay and health care expenditures are estimated annually treatment for NI to $\$ 4.5$ billion to $\$ 11$ billion and contribute to 88000 deaths in the U.S. [3, 9].

Additionally, many pathogenic species has been found which are able to cause HAIs in health care settings. It has been documented that, the hospital environment (equipment, materials and work surface) are considered as reservoir and play a role in the prolonged maintenance of NI and transmission [10]. In several studies, bacteria are the most predominant infectious agents $(85 \%)[7,8,11]$. Laxity in applying basic hygiene actions (individual or collective) has increased the incidence of this phenomenon over the last thirty years. This has become so extensive that international and national authorities are getting more implicated in managing this problem [7,9]. However, the population at risk are Patients, Health care-workers, staff and visitors [7, $12,13]$. Those more susceptible are those with disorders. Also new invasive diagnostics methods, antibiotics selection pressure, and poor personal hygiene are responsible of NI outbreaks [7]. In Low-and Middle -Income countries, recent analyses by World Health Organisation (WHO) has found that other factors include: inadequate environmental hygienic conditions, waste disposal; poor infrastructure; insufficient equipment; understaffing; overcrowding; poor knowledge and application of basic infection control measures; lack of procedure; lack of knowledge of injection and blood transfusion safety; absence of local and national guidelines and policies are warning risk factors of NI [14]. In 2011 WHO report an urgent need for HAIs surveillance and to gather data on the actual burden on a regular basis [15]. In some developed countries, the surveillance system exist and provide regular reports on national trends of endemic HAI, such as the National Healthcare Safety Network of the United States of America or the German Hospital Infection Surveillance System and the Europe Link for Infection Control through Surveillance"(HELICS). In developing countries, the magnitude of the problem is even unknown largely and, furthermore control practices remain rudimentary $[5,15]$. Often misunderstood or denied, there is a paucity of information on nosocomial infection in Subtropical Africa shows by a review of recent medical literature [16]. Now more than ever, specific surveillance is needed in order to enact early detection MDR agents and prevention strategies to curtail NI [1].

Studies on the effectiveness of interventions to reduce HAIs are limited, In Cameroon, few studies show the incidence of NI varies between 16.9-21.5\% and Health care systems has not yet encouraged hospitals to expand practices focusing on the prevention and monitoring of infectious agents $[4,6]$. This worrying situation needs to be questioned and targeted actions have to be carried out in order to help the population. Surveillance of hospital reservoir to prevent HAIs is central to provide high quality and safe healthcare, even in settings with limited resources where there are poor applications of best disinfection, sterilization and cleaning procedure $[4,8]$. Our study has as objective to assess major bacteria species in various units of four hospitals of Littoral Region of Cameroon.

\section{Materials and Methods}

\subsection{Study Site}

The study site were selected bases to the following parameters: the different technical platform, attendance (social level and frequency), care offered (primary, secondary and central health care according to Cameroon health system) and units. Four hospital structure corresponding to the different level of organization (private and public sector) were selected: Saint Jean de Malte Hospital of Njombe (HSJMN), Military Hospital of Douala (MHD), New Bell District Hospital (NBDH) and Medical Health Center of Ndokoti (MHCN) of were used for the study.

\subsection{Study Design}

A descriptive, cross-sectional laboratory based study was performed. We collected swaps for culture from seven units (Medical, Operating Theatre, Laboratory, Surgical, Emergency and Maternity) specific environmental points (10 different equipment and 10 different materials) in the four hospitals between December 2018 to May 2019. For selection expected reservoir sample.

\subsection{Sample Collection and Technique}

In each health facility, simple random sampling technique was used to collect the sample. Consideration were given to equipment and material with constant hand contacts. This 
included 10 equipment like: treatment tables, operating tables, delivery tables, office tables, anaesthesia equipment, surgical aspirators, oxygen concentrators, wheelchairs, patients and office chairs. 10 materials: fans, patient bedside tables, patients bed rails, trolleys, door handles, negastoscopes, baby scales, air conditioners, Antiseptic container boxes and Antiseptic container covers. Collection was done in the mornings after disinfection but before start of work in each unit. This was done by swabbing all selected equipment and materials using sterile swabs moistened in sterile normal saline. These swabs were placed in labeled caps with unit and type of equipment or material identification numbers and immediately transported to the microbiology laboratory for processing.

\subsection{Laboratory Processing}

Specimens were inoculated directly according to good laboratory practice on four agar media consecutively (three sectors petri disk with different medium Eosine methylene blue, CLED, Mannitol salt agar and the blood agar medium in one sector petrie disk) Microxpress ${ }^{\circledR}$ ISO 9001:2008 EN ISO 13485:2012. After inoculation, the three sectors media were incubated overnight at $37^{\circ} \mathrm{C}$ aerobically for 24 hours and blood agar medium anaerobically up to a maximum of 48 hours and inspected for bacterial growths. Identification of bacteria to species level was done using colony characteristics, Gram's staining techique, different biochemical tests comprising of; oxidase, catalase, coagulase, motility test, urease, indole and API Staph, API Strepto and API $20 \mathrm{E}^{\mathrm{TM}}$ BioMerieux according to standard methods [17]. Review of the results was done by the microbiologist officer at the laboratory to ensure quality control.

\subsection{Ethical Consideration}

An ethical clearance were obtained from Institutional Ethics committee for research on Human Health of the University of Douala: No: 1646 IEC-UD/06/2018/T. Also, all afferent administrative authorizations to carry out the project was obtained from the Director of the four hospitals (HSJMN, NBDH, MHD and MHCN).

\subsection{Statistical Analysis}

Data were recorded in Microsoft Excel 2013 and later transferred to SPSS version 23 software. Categorical variables; clinical factors was summarized using counts, percentages and proportions. Group comparisons for categorical variables were done using the chi-square test (Fisher's exact test) to find any significance at $\mathrm{P}<0.05$.

\section{Results}

\subsection{Result of Culture and Forms of Bacteria Isolated}

A total of 236 specimens of different hospital equipment and materials were sampled and inoculated in specific media. Looking at the growth and general forms of bacteria isolated, it was observed that majority 119 showed positive bacteria growth, giving a prevalence rate of $50.42 \%$. Among them, 62 (52.10\%) were Gram positive cocci, 57 (47.90\%) Gram negative bacilli. The above explanation is illustrated in the figure 1 below.

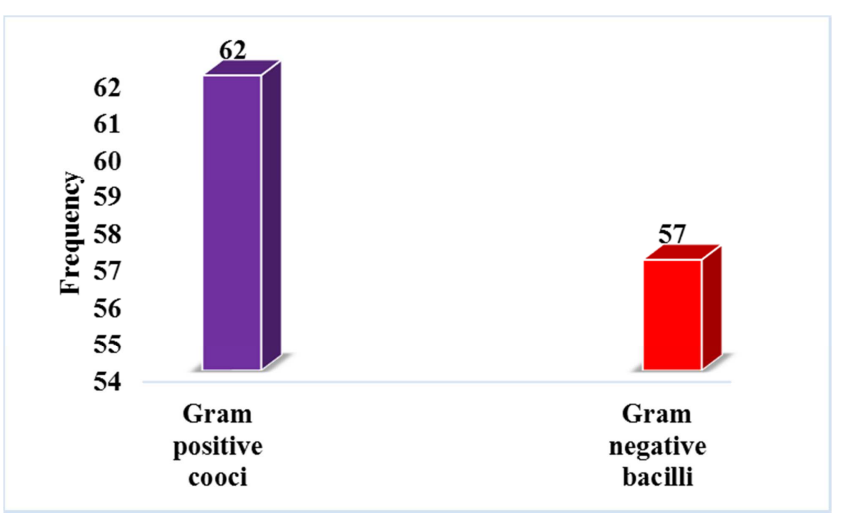

Figure 1. General frequency of forms of bacteria isolated.

\subsection{Type of Hospital Equipment and Material According to Forms of Bacteria Isolated}

Looking at the forms of bacteria isolated from hospital equipment and materials, it was noted that the patient bedside tables, office chairs, patients bed rails and antiseptic container boxes showed growth with highest percentage respectively $11.76 \%(14 / 119), 10.92 \% \quad(13 / 119), 10.08 \%$ $(12 / 119)$ and $9.24 \%(11 / 119)$. Gram positive cocci were the major bacteria forms isolated; the office chairs and patients' beds rail showed the highest percentage $(8.40 \%)(10 / 19)$, followed by the patients' bedside tables with $7.56 \%(9 / 119)$. Gram negative bacilli, were found on antiseptic container boxes $(5.88 \%(7 / 119))$, trolley $(5.04 \%(6 / 119))$ and treatment tables, fans and patient beside tables with $4.2 \%(5 / 119)$. These detailed result of the above explanation was tabulated and illustrated as shown in table 1 below.

Table 1. Type of hospital equipment and material according to forms of bacteria isolated.

\begin{tabular}{|c|c|c|c|}
\hline Form of bacteria isolated Type of hospital equipment & Gram positive cocci & Gram negative bacilli & Total \\
\hline Treatment tables & $4(3.36 \%)$ & $5(4.20 \%)$ & $9(7.56 \%)$ \\
\hline Fans & $3(2.52 \%)$ & $5(4.20 \%)$ & $8(6.72 \%)$ \\
\hline Door handles & $2(1.68 \%)$ & $4(3.36 \%)$ & $6(5.04 \%)$ \\
\hline Patient bedside table & $9(7.56 \%)$ & $5(4.20 \%)$ & $14(11.76 \%)$ \\
\hline Patient bed rails & $10(8.40 \%)$ & $2(1.68 \%)$ & $12(10.08 \%)$ \\
\hline Trolleys & $4(3.36 \%)$ & $6(5.04 \%)$ & $10(8.40 \%)$ \\
\hline Office chairs & $10(8.40 \%)$ & $3(2.52 \%)$ & $13(10.90 \%)$ \\
\hline Wheel chairs & $5(4.20 \%)$ & 0 & $5(4.20 \%)$ \\
\hline Antiseptic container covers & 0 & $3(2.52 \%)$ & $3(2.52 \%)$ \\
\hline
\end{tabular}




\begin{tabular}{llll}
\hline Form of bacteria isolated Type of hospital equipment & Gram positive cocci & Gram negative bacilli & Total \\
\hline Antiseptic container boxes & $4(3.36 \%)$ & $7(5.88 \%)$ & $11(9.24 \%)$ \\
Baby scales & $1(0.84 \%)$ & 0 & $1(0.84 \%)$ \\
Anesthesia equipments & $1(0.84 \%)$ & $1(0.84 \%)$ & $2(1.68 \%)$ \\
Air conditioners & $1(0.84 \%)$ & $1(0.84 \%)$ & $2(1.68 \%)$ \\
Delivery tables & 0 & $2(1.68 \%)$ & $2(1.68 \%)$ \\
Oxygen concentrations & 0 & $1(0.84 \%)$ & $1(0.84 \%)$ \\
Patient chairs & $5(4.20 \%)$ & $4(3.36 \%)$ & $9(7.56 \%)$ \\
Operating tables & 0 & $2(1.68 \%)$ & $2(1.68 \%)$ \\
Surgical aspirators & 0 & $1(0.84 \%)$ & $1(0.84 \%)$ \\
Negatoscopes & 0 & $1(0.84 \%)$ & $1(0.84 \%)$ \\
Office tables & $3(2.52 \%)$ & $4(3.36 \%)$ & $7(5.88 \%)$ \\
Total & $62(26.3 \%)$ & $57(24.2 \%)$ & $119(100 \%)$ \\
\hline
\end{tabular}

\subsection{Profile and Prevalence of Bacteria Isolated}

Among the total 119 bacteria isolated, 33 different species were found to belong to 5 Gram-positivecocci and 27 Gram negative bacilli (13 Enterobacteriaceae and 15 non enterobacteria). In general as Gram positive cocci were mostly identified to be Staphylococcus aureus with $37.811 \%$ (45/119), followed by Staphylococcus epidermidis $8.40 \%$ (10/119), Staphylococcus saprophyticus and Microccocus spp both having $2.52 \%(3 / 119)$ and Enterococcus faecalis $0.84 \%$ $(1 / 119)$. On the basis of Gram negative bacilli isolated, majority was non Enterobateriaceae $26.05 \%$ (31/119) with a highest percentage of Acinetobacter spp, Aeromonas hydrophilas and Pasteurella pneumotropica equal having $3.36 \% 5$ (4/119), followed by Enterobacteriaceae family $21.85 \%(26 / 119)$ where E. coli showed a highest percentage $(5.04 \%(6 / 119))$. Figure 2, Figure 3 below and Figure 4 shows a detailed illustration of the above explanation.

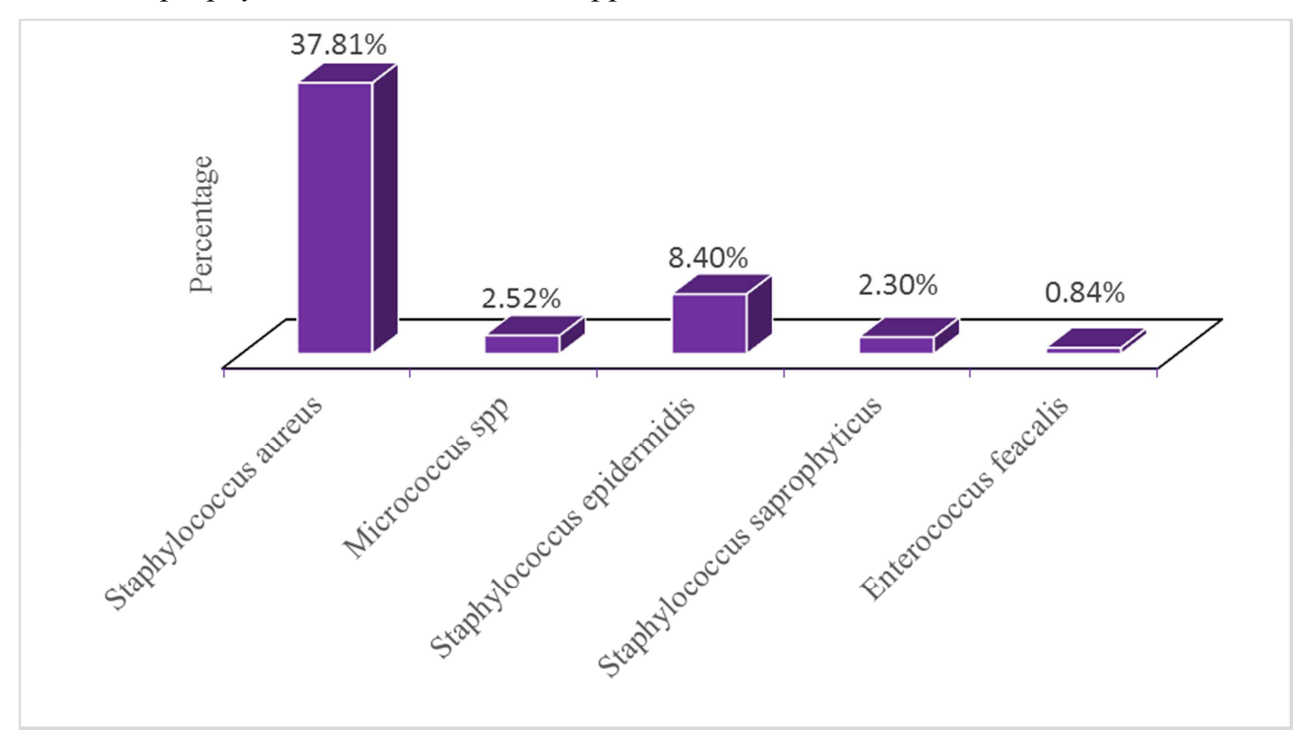

Figure 2. General prevalence of Gram positive cocci in the targeted hospital facilities.

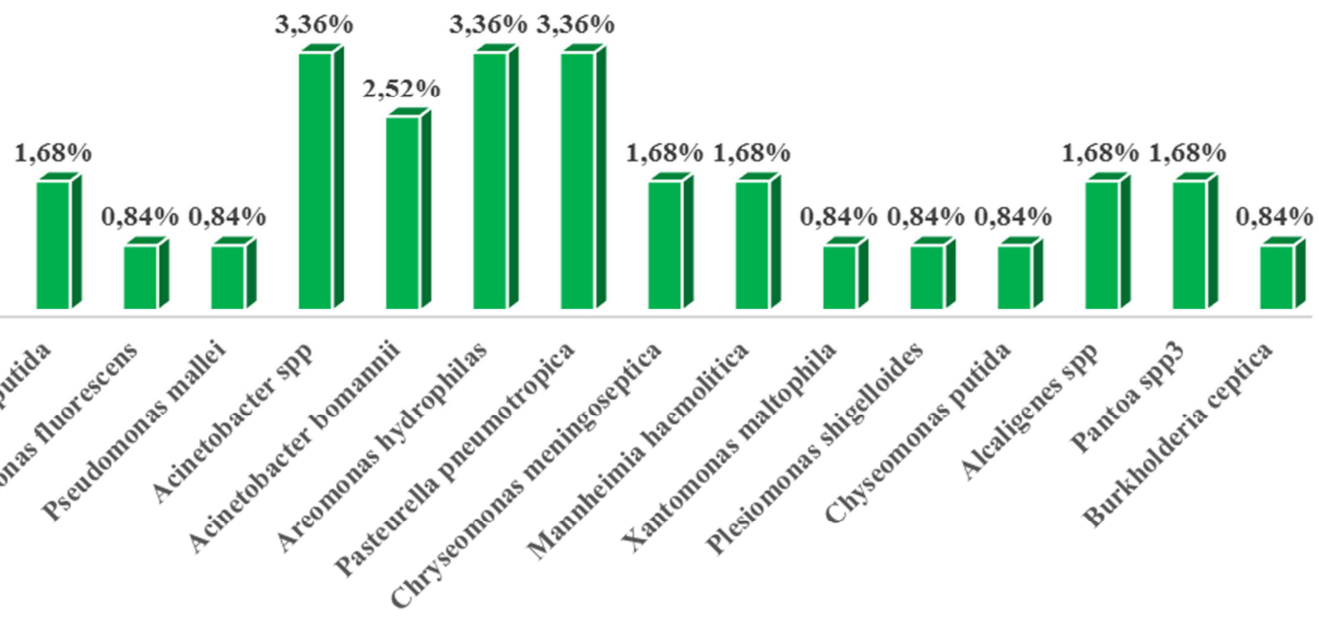

Figure 3. General profile and prevalence of Gram negative, non Enterobacteriaceae species in the hospitals facilities. 


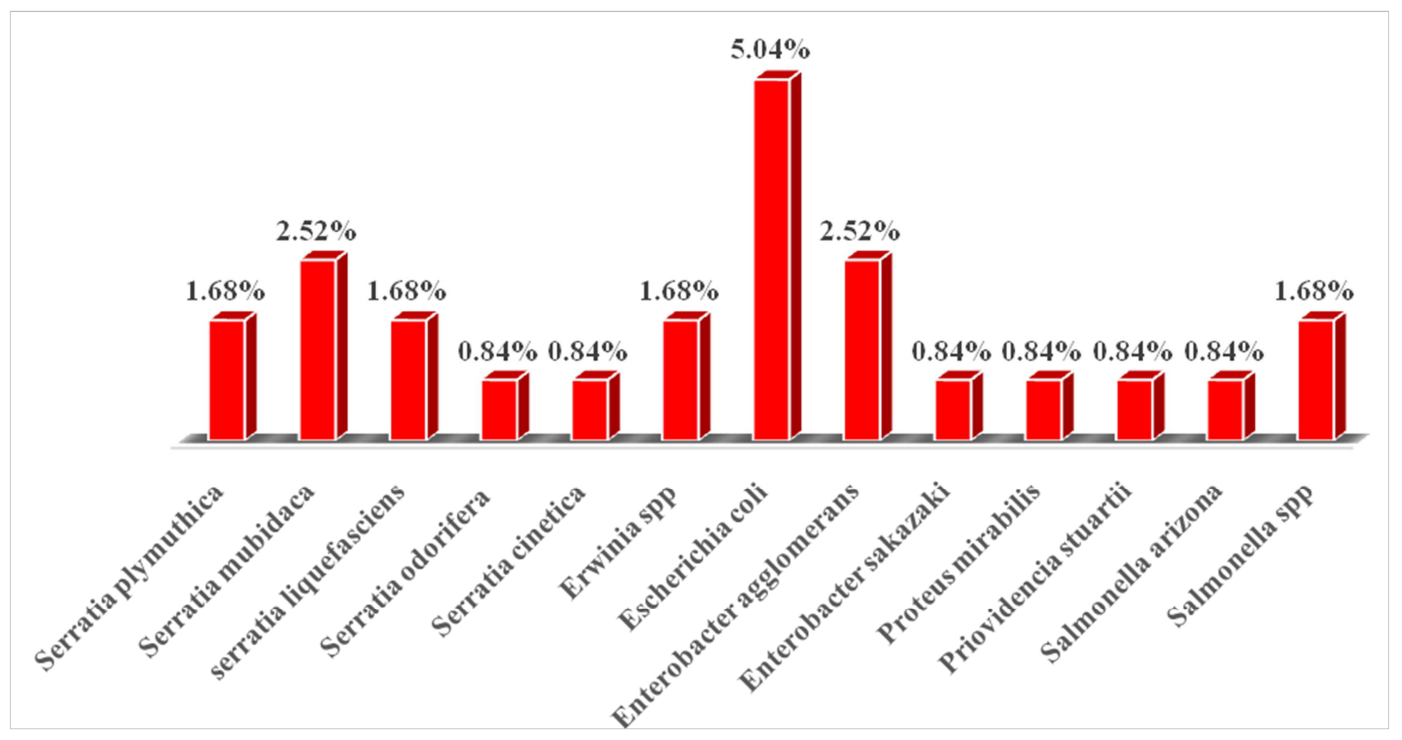

Figure 4. General profile and prevalence of Gram negative, Enterobacteriaceae species in the hospitals facilities.

\subsection{Distribution of Bacteria Isolates Per Hospital Facilities}

Out of 62 Gram positive cocci isolated, 26 (41.93\%) were found in the MHD, followed by NBDH with 16 (25.80) with Enterococus feacalis was the only. MHCN showed the lowest count of just $5(8.06 \%)$, while, the predominant and only species found in all hospital was $S$. aureus with $72.58 \%$ $(45 / 62)$. However, the rest of the other bacterial species isolated were found in some hospital and absent in others. For 26 Enterobacteriaceae distribution, out of the four hospital centers, HSJMN showed a highest bacterial contamination level $30.70 \%(8 / 26)$ with a majority of Enterobacter agglomerans $11.53 \%(3 / 26)$ as well as from the only center it was isolated. Followed by $\mathrm{NBDH}, \mathrm{MHCN}$, and
MHD having each one $23.07 \%(6 / 26)$, constituting most of $E$. coli both NBDH, MHCN and Ervinia spp in MHD where it was only isolated. According to 31 non enterebacteriaceae Gram negative bacilli isolated, NBDH hosted the highest proportion (32.25\% (10/31)) mostly made up of Pantoa spp $6.45 \%(2 / 31)$ also only isolated there. Likewise, even if MHCN showed the lowest percentage $16.12 \%(5 / 31)$ of bacteria isolated it was the only center reported the growth of Pseudomonas pudita as well as the most species with $6.45 \%$ (2/31). In addition just one strain of Burkholdera ceptica was isolated in MHD 3.32\% (1/31) Tables 2, 3 and 4 below shows a detailed illustration of the above explanation.

Table 2. Distribution of Gram positive cocci per hospital facilities.

\begin{tabular}{llllll}
\hline \multirow{2}{*}{ Isolated Gram positive cocci } & NBDH & HSJMN & MHCN & MHD & TOTAL \\
\cline { 2 - 6 } & $\mathbf{n}(\mathbf{\%})$ & $\mathbf{n}(\mathbf{\%})$ & $\mathbf{n}(\mathbf{\%})$ & $\mathbf{n}(\mathbf{\%})$ & n (\%) \\
\hline Staphylococcus aureus & $12(19.35 \%)$ & $9(14.51 \%)$ & $4(6.45 \%)$ & $20(32.25 \%)$ & $45(72.58 \%)$ \\
Micrococcus Spp & $1(1.61 \%)$ & 0 & 0 & $2(3.22 \%)$ & $3(4.83 \%)$ \\
Staphylococcus epidermitidis & $2(3.22 \%)$ & $6(9.67 \%)$ & 0 & $2(3.22 \%)$ & $10(16.12 \%)$ \\
Staphylococcus saprophyticus & 0 & 0 & $1(1.61 \%)$ & $2(3.22 \%)$ & $3(4.83 \%)$ \\
Enterococcus faecalis & $1(1.61 \%)$ & 0 & 0 & 0 & $1(1.61 \%)$ \\
Total & $16(25.80 \%)$ & $15(24.19 \%)$ & $5(8.06 \%)$ & $26(41.93 \%)$ & $62(100 \%)$ \\
\hline
\end{tabular}

Table 3. Distribution of Gram negative bacilli enterobacteriaceae per hospital facilities.

\begin{tabular}{llllll}
\hline Isolated Gram negative & NBDH & HSJMN & MHCN & MHD & TOTAL \\
\cline { 2 - 6 } enterobacteriaceae & $\mathbf{n}(\mathbf{\%})$ & $\mathbf{n}(\mathbf{\%})$ & $\mathbf{n}(\mathbf{\%})$ & $\mathbf{n}(\mathbf{\%})$ & $\mathbf{n}(\mathbf{\%})$ \\
\hline S. phymutica & $1(3.84 \%)$ & 0 & 0 & $1(3.84 \%)$ & $2(7.69 \%)$ \\
S. mublidaca & $1(3.84 \%)$ & $1(3.84 \%)$ & 0 & $1(3.84 \%)$ & $3(11.53 \%)$ \\
S. liquefasciens & 0 & $2(7.69 \%)$ & 0 & 0 & $2(7.69 \%)$ \\
S. cinetica & 0 & $1(3.84 \%)$ & 0 & 0 & $1(3.84 \%)$ \\
Erwinia spp & 0 & 0 & 0 & $2(7.69 \%)$ & $2(7.69 \%)$ \\
E. coli & $3(11.53 \%)$ & 0 & $3(11.53 \%)$ & 0 & $6(23.07 \%)$ \\
E. agglomerans & 0 & $3(11.53 \%)$ & 0 & 0 & $3(11.53 \%)$ \\
E. sakazaki & 0 & $1(3.84 \%)$ & 0 & 0 & $1(3.84 \%)$ \\
P. mirabilis & $1(3.84 \%)$ & 0 & 0 & 0 & $1(3.84 \%)$ \\
S. arizona & 0 & 0 & $1(3.84 \%)$ & 0 & $1(3.84 \%)$ \\
salmonella spp & 0 & 0 & $1(3.84 \%)$ & $1(3.84 \%)$ & $2(7.69 \%)$ \\
S. odorifera & 0 & 0 & 0 & $1(3.84 \%)$ & $1(3.84 \%)$ \\
P. stuartii & 0 & 0 & $1(3.84 \%)$ & 0 & $1(3.84 \%)$ \\
\hline
\end{tabular}




\begin{tabular}{|c|c|c|c|c|c|}
\hline \multirow{2}{*}{$\begin{array}{l}\text { Isolated Gram negative } \\
\text { enterobacteriaceae }\end{array}$} & NBDH & HSJMN & MHCN & MHD & TOTAL \\
\hline & n (\%) & n (\%) & n (\%) & n (\%) & n (\%) \\
\hline TOTAL & $6(23.07 \%)$ & $8(30.70 \%)$ & $6(23.07 \%)$ & $6(23.07 \%)$ & $26(100 \%)$ \\
\hline
\end{tabular}

S.phymutica=Serratia phymutica, S.mublidaca=Serreatia mublidaca, S.liquefaciens=Serratia liquefaciens, S.cinatica=Serratia cinetica, S.odorifrea=Serratia odorifera, E.coli=Escherichia coli.

E.agglomerans=Enterobater agglomerans, E.sakasaki=Enterobacter sakasaki.

P.mirabilis=Proteus mirabilis, S.arizona=Salmonella arizona, P.stuartii=Providencia stuartii.

Table 4. Distribution of Gram negative bacilli non enterobacteriaceae per hospital facilities.

\begin{tabular}{llllll}
\hline Isolated Gram negative non & NBDH & HSJMN & MHCN & MHD & TOTAL \\
\cline { 2 - 6 } enterobacteriaceae & $\mathbf{n}(\mathbf{\%})$ & $\mathbf{n}(\mathbf{\%})$ & $\mathbf{n}(\mathbf{\%})$ & n (\%) & n (\%) \\
\hline P. Putida & 0 & 0 & $2(6.45 \%)$ & 0 & $2(6.45 \%)$ \\
P. fluorescens & $1(3.22 \%)$ & 0 & 0 & 0 & $1(3.22 \%)$ \\
P. mallei & 0 & $1(3.22 \%)$ & 0 & 0 & $1(3.22 \%)$ \\
A. baumannii & $1(3.22 \%)$ & $1(3.22 \%)$ & 0 & $1(3.22 \%)$ & $3(9.67 \%)$ \\
Acitebacter spp & $1(3.22 \%)$ & $3(9.67 \%)$ & 0 & 0 & $4(12.9 \%)$ \\
A. hydrophilas & $1(3.22 \%)$ & 0 & $1(3.22 \%)$ & $2(6.45 \%)$ & $4(12.9 \%)$ \\
P. pneumotropica & $1(3.22 \%)$ & 0 & 0 & $3(9.67 \%)$ & $4(12.9 \%)$ \\
C. meningoceptica & $1(3.22 \%)$ & 0 & 0 & $1(3.22 \%)$ & $2(6.45 \%)$ \\
M. heamoliticus & $1(3.22 \%)$ & $1(3.22 \%)$ & 0 & 0 & $2(6.45 \%)$ \\
X. maltophila & 0 & $1(3.22 \%)$ & 0 & 0 & $1(3.22 \%)$ \\
P. shigelloides & 0 & 0 & $1(3.22 \%)$ & 0 & $1(3.22 \%)$ \\
C. putida & 0 & 0 & $1(3.22 \%)$ & 0 & $1(3.22 \%)$ \\
Alcaligenes spp & $1(3.22 \%)$ & 0 & 0 & 0 & $2(6.45 \%)$ \\
Pantoa ssp" & $2(6.45 \%)$ & 0 & 0 & 0 & $2(3.22 \%)$ \\
B. ceptica & 0 & 0 & 0 & $1(3.22 \%)$ & $1(3.45 \%)$ \\
TOTAL & $10(32.25 \%)$ & $7(22.58 \%)$ & $5(16.12 \%)$ & $9(29.03 \%)$ & $31(100 \%)$ \\
\hline
\end{tabular}

P. putuda=Pseudomonas putida, $P$. florescens=Pseudomonas florescens, P. mallei=Pseudomonas mallei.

A. baumanni $=$ Acinetobacter baumannii, A. hydropilas $=$ Aeromonas hydrophylas,

P. pneumotropica $=$ Pasteurella pneumotropica, C.meningoeptica $=$ Chryseomonas meningoceptica,

M. heamolyticus $=$ Manhemia haemolyticus, X.maltophila=Xantomonas maltophila,

P. shigelloides $=$ Plesiomonas shigelloides, $\mathrm{C}$. putida $=$ Chryseomonas putida, $\mathrm{B}$. ceptica $=$ Burkholderia ceptica .

\subsection{Distribution of Bacterial Isolated According to Hospital Units}

In each of the four hospital facilities, we grouped the isolate according to hospital units. Out of the 62 Gram positive cocci, the Emergency unit and maternity showed both the highest bacterial growth $19.35 \%(12 / 62)$, while the pediatric units were the lowest with $8.06 \%(5 / 62)$. Staphylococcus aureus was the most common species and found in all units. However, the others of Gram positive cocci were found in some units and absent in others, except the single strain of Enterococcus faecalis isolated in medical ward $1.61 \%(1 / 62)$. Regarding the 26 Gram negative bacilli enterobacteriaceae family, the highest level of bacterial isolates were recovered in laboratory $26.92 \%$ (7/26), in which E. coli was predominantly reported $(15.38 \%$ (4/26)) and the lowest organism isolated from operating units was a single strain of Salmonella odorifera 3.38\% (1/26). Similarly, of the 13 species isolated in this enterobacteriaceae family 5 note to be singly found $3.38 \%(1 / 26)$ in different units, they include: Serratia cinetica (Surgical unit), Enterobacter sakasaki (Maternity), Proteus mirabilis (Medical unit), Salmonella arizona (Pediatric unit) and Providencia stuartii (Laboratory). Furthermore, Gram negative bacilli were mostly by 31 identified non enterobacteriaceae. The Emergency units $35.48 \%$ (11/31) followed by Pediatric 19.35\% (6/31) hosted the highest percentages respective by Chryseomonas meningoseptica, Mannhemia haemolytica both $6.45 \%(2 / 31)$ and Aeromonas hydrophilas 9.67\% (3/31) respectively. In addition, likewise in the enterobacteria family, in this group, out of the 15 species isolated, 6 were singularly isolated in various units $3.22 \% \quad(1 / 31) \quad$ (Pseudomonas mallei, Plesiomonas shigelloides and Chryseomonas putida (Emergency unit), Pseudomonas fluorescence and Burkholderia ceptica (Operating unit), and Xanthomonas maltophilas (Maternity)). The detailed of these finding are illustrated in tables 5, 6 and 7 below.

Table 5. Distribution of Gram positive cocci per hospital units.

\begin{tabular}{lllllllll}
\hline \multirow{2}{*}{ Isolated Gram positive cocci } & $\begin{array}{l}\text { Pediatric } \\
\text { unit }\end{array}$ & Medical unit & $\begin{array}{l}\text { Operating } \\
\text { Theatre }\end{array}$ & Laboratory & Surgical unit & $\begin{array}{l}\text { Emergency } \\
\text { unit }\end{array}$ & Maternity & TOTAL \\
\cline { 2 - 8 } & $\mathbf{n}(\%)$ & $\mathbf{n}(\%)$ & $\mathbf{n}(\%)$ & $\mathbf{n}(\%)$ & $\mathbf{n}(\%)$ & n (\%) & $\mathbf{n}(\%)$ & $\mathbf{n}(\%)$ \\
\hline Staphylococcus aureus & $3(4.83 \%)$ & $7(11.29 \%)$ & $6(9.67 \%)$ & $7(11.29 \%)$ & $5(8.06 \%)$ & $9(14.51 \%)$ & $8(12.90 \%)$ & $45(72.58 \%)$ \\
Micrococcus Spp & 0 & 0 & 0 & $1(1.61 \%)$ & $1(1.61 \%)$ & $1(1.61 \%)$ & 0 & $3(4.83 \%)$ \\
Staphylococcus epidermitidis & $1(1.61 \%)$ & $2(3.22 \%)$ & 0 & 0 & $2(3.22 \%)$ & $1(1.61 \%)$ & $4(6.45 \%)$ & $10(16.12 \%)$ \\
Staphylococcus saprophyticus & $1(1.61 \%)$ & 0 & 0 & 0 & $1(1.61 \%)$ & $1(1.61 \%)$ & 0 & $3(4.83 \%)$ \\
Enterococcus faecalis & 0 & $1(1.61 \%)$ & 0 & 0 & 0 & 0 & 0 & $1(1.61 \%)$ \\
TOTAL & $5(8.06 \%)$ & $10(16.12 \%)$ & $6(9.67 \%)$ & $8(12.90 \%)$ & $9(14.51 \%)$ & $12(19.35 \%)$ & $12(19.35 \%)$ & $62(100 \%)$ \\
\hline
\end{tabular}


Table 6. Distribution of Gram negative bacilli enterobacteriaceae per hospital units.

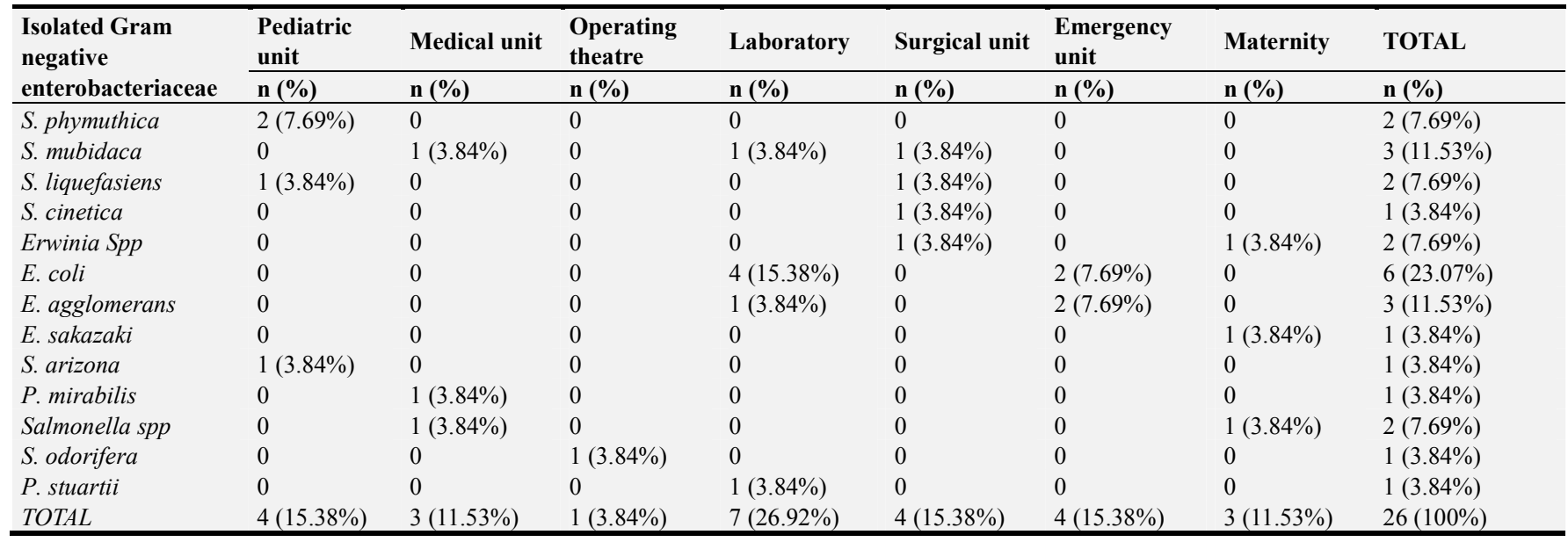

Table 7. Distribution of Gram negative bacilli non enterobacteriaceae per hospital units.

\begin{tabular}{|c|c|c|c|c|c|c|c|c|}
\hline \multirow{2}{*}{$\begin{array}{l}\text { Isolated Gram negative non } \\
\text { enterobacteriaceae }\end{array}$} & $\begin{array}{l}\text { Pediatric } \\
\text { unit }\end{array}$ & Medical unit & $\begin{array}{l}\text { Operating } \\
\text { Theatre }\end{array}$ & Laboratory & Surgical unit & $\begin{array}{l}\text { Emergency } \\
\text { unit }\end{array}$ & Maternity & TOTAL \\
\hline & n (\%) & n (\%) & n (\%) & n (\%) & n (\%) & n (\%) & n (\%) & n (\%) \\
\hline P. Pituda & 0 & $1(3.22 \%)$ & 0 & $1(3.22 \%)$ & 0 & 0 & 0 & $2(6.45 \%)$ \\
\hline P. fluoresens & 0 & 0 & $1(3.22 \%)$ & 0 & 0 & 0 & 0 & $1(3.22 \%)$ \\
\hline P. mallei & 0 & 0 & 0 & 0 & 0 & $1(3.22 \%)$ & 0 & $1(3.22 \%)$ \\
\hline A. bomannii & $1(3.22 \%)$ & 0 & $1(3.22 \%)$ & 0 & 0 & $1(3.22 \%)$ & 0 & $3(9.67 \%)$ \\
\hline Acinetobacter spp & 0 & $1(3.22 \%)$ & $1(3.22 \%)$ & 0 & $1(3.22 \%)$ & $1(3.22 \%)$ & 0 & $4(12.90 \%)$ \\
\hline P. pnemotropica & $2(6.45 \%)$ & $1(3.22 \%)$ & 0 & $1(3.22 \%)$ & 0 & 0 & 0 & $4(12.90 \%)$ \\
\hline C. meningoseptica & 0 & 0 & 0 & 0 & 0 & $2(6.45 \%)$ & 0 & $2(6.45 \%)$ \\
\hline M. haemolitica & 0 & 0 & 0 & 0 & 0 & $2(6.45 \%)$ & 0 & $2(6.45 \%)$ \\
\hline$X$. maltophilas & 0 & 0 & 0 & 0 & 0 & 0 & $1(3.22 \%)$ & $1(3.22 \%)$ \\
\hline P. shigelloides & 0 & 0 & 0 & 0 & 0 & $1(3.22 \%)$ & 0 & $1(3.22 \%)$ \\
\hline C. putida & 0 & 0 & 0 & 0 & 0 & $1(3.22 \%)$ & 0 & $1(3.22 \%)$ \\
\hline Alcaligenes spp & 0 & 0 & $1(3.22 \%)$ & 0 & 0 & $1(3.22 \%)$ & 0 & $2(6.45 \%)$ \\
\hline TOTAL & $6(19.35 \%)$ & $3(9.67 \%)$ & $5(16.45)$ & $2(6.45 \%)$ & $2(6.45 \%)$ & $11(35.48 \%)$ & $2(6.45 \%)$ & $31(100 \%)$ \\
\hline
\end{tabular}

\section{Discussion}

\subsection{Result of Culture According to the Profile and Prevalence of Bacteria Isolaazted}

Bacteria are the mostly pathogens causing nosocomial infections. Gram positive cocci and Gram negative bacilli keep and important place in medical bacteriology. Therefore, laboratory control play a key role in the assessment of this problem and must be used to identify common pathogens to their species level. In general our study revealed a total of 119 bacterial growth out of 236 swabs collected, giving an overall prevalence of bacterial contamination of $50.4 \%$. Our findings is high than those found in Kawolo General Hospital in Uganda where among 136 swabbed samples, 61 (44.2\%) presented bacterial contaminants [10]. These results are consistent in terms of type of bacteria found: 64/119 (52.10\%) Gram positive cocci and 57/119 (47.90\%) Gram negative bacilli (figure 1), compare to only $46(75.4 \%)$ Gram-positive cocci and 15 (24.6\%) Gram-negative bacilli respectively [10]. Besides, our study recovered 33 different species, whereas more the Uganda study 14 different organisms were reported in Mbale Regional Referral Hospital. On the different surfaces and settle plate establishment in 4 various operating theatres were swabbed and cultured [11]. This difference can be explained by obvious fact like distinction in study area, sample size, target articles brief methodology. However our results presented a predominance of $S$. aureus, as the most infecting agent 45/119 (37.81\%) followed by E. coli 6/119 (5.04\%) and Acinetobacter spp 4/119 (3.36\%) (Figures 2, 3 and 4). This results is similar to others findings, revealed that the high frequency of isolation were $S$. aureus and $E$. coli $[18,19]$. Thus, our results suggest that these microbes in hospital environment may be the source of nosocomial infections, especially as these isolates are associated with HAIs. This can be supported by the fact two of our major isolates $(S$. aureus and Acinetobacter spp), belongs to the three of the priority pathogens on the WHO list for Global Antimicrobial Resistance Surveillance System (GLASS) reporting, namely Klebsiella pneumonia, Acinetobacter baumannii and Staphylococcus aureus to cause HAIs [20]. This shows poor application of best disinfection, sterilization and cleaning 
common in Sub-Saharan Africa where Nosocomial infections have long been neglected [4, 9, 21]. Moreover, These results are consistent with a study carry in teaching hospital in Northwest Ethiopia where clinical samples of 260 hospitalized patients suspected of having nosocomial infections where culture positive, $66.5 \%$ mostly to Grampositive cocci (S. aureus 35\%) and Gram negative bacilli (E. coli 15.3\%) [18]. Elsewhere a study from Kawolo General Hospital in Uganda reported, $S$. aureus with the highest prevalence 46/61 (75.4\%) [10]. On contrary our findings are different for some studies carry out in Cameroon (surveillance of nosocomial infections in YUTH) and Uganda (contamination of microbial pathogens in 4 operating theatre), where Klebsiella spp (27\%), Pseudomonas spp (23.9) and Bacillus spp (17.5\%) were found as common organisms respectively $[6,11]$. This difference can be due to the type and level of target hospital, units, type of specimen (hospital environment \& hospitalized patients) and sample size.

\subsection{Type of Hospital Equipment and Material According to Forms of Bacteria Isolated}

In general, compared to the material and equipment swabbed, patient bedside tables, office chairs and patient bed rails showed growth with highest percentage respectively $11.76 \%(14 / 119), 10.92 \%(13 / 119)$ and $10.08 \%(12 / 119)$ (Table 1). This is proximate with the results of Sserwadda et $a l$ in Uganda where patient beds had the highest bacterial contamination levels of $19 \%(12 / 61)$. This can be explained by the contamination of hands by the patients, visitors and during patient care as most authors have reported those medical workers' hands are the most probable means of transfer $[10,22]$. However, it is different to a study carried out in 2018 by other authors in Uganda were instrument trolleys, operating beds, and door handles had the highest number of pathogens respectively $26 \%, 20 \%$ and $10 \%$ [11].

\subsection{Profile and Prevalence of Bacteria Isolated According to the Four Hospital Facilities and Seven Units}

Comparing the level of contamination of bacterial between the four hospital facilities and the 7 hospital units, in our study, we observed that the major hospital facilities and units contaminated varied according to various type and species of isolated bacteria. According to hospital facilities, for Gram-positive cocci, MHD (41.93\%) mostly S. aureus $32.25 \%$, Gram negative bacilli Enterobacteriaceae, HSJMN (30.70\%) mainly E. agglomerans $11.53 \%$, (Tables 2, 3, 4). Regarding hospital units for Gram-positive cocci, Emergency units and maternity $(19.35 \%)$ majority $S$. aureus $14.51 \%$ and $12.90 \%$ respectively, Gram negative bacilli enterobacteriaceae, Laboratory $(26.92 \%)$ frequently $E$. coli $15.38 \%$ and non enterobacteriacea, Emergency unit mostly C. meningoseptica and $M$. heamolytica both $6.45 \%$ (Tables 5, 6 an 7). This has been confirmed by Saxenal et al. 2019 indicating the variability of organisms causing infections widely from one country to another; as well as from one hospital to other and even among different services [23]. Nevertheless $S$. aureus was the only species found in all hospitals and units. This could be explained by the fact that it can be due to a resistant pattern such as MRSA, responsibly for an outbreak and spread in different services. This can be supported by a study that reported the presence and increase of MRSA in Many hospitals of several countries in Africa [24]. On the contrary our findings are different from the studies of Nouetchognou et $a l$ and Bashir et $a l$ who conducted in and Yaounde University Teaching Hospital in Cameroon and three tertiary hospitals, Kano state, Nigeria, where Klebsiella spp were the most frequently isolated bacterial nosocomial pathogens from all units and all studied hospitals respectively $[6,25]$.

There is a high level of contamination in our hospital environment. Such contamination is suggestive of a variety of factors which may include; poor decontamination and sanitation practices, ineffective disinfectants use and ineffective sterilization of medical care articles as stated by Sserwadda in 2018 [10].

\section{Conclusion}

HAIs remain today a public health problem with the presence and diffusion of germ in all hospital units, material and equipment. Our study clearly demonstrates that all hospital facilities, materials and equipment in all the units were contaminated with bacteria. Gram positive cocci were most isolated. S. aureus 45/62 (72.58\%) found in all hospital facilities. The other bacterial species isolated were found in some hospitals, units and absent in others. Patient bedside tables, office chairs and patient bed rails showed growth with highest percentage. Thus, one of the key approaches that we need to prevent and control NI, is to recognize the level risk to pass on the on infections. The data from this study indicate the instruments contaminated with bacteria are a source and reservoir for horizontal transmission of HAIs. This situation is worrying and alarming for developing countries like Cameroon. Therefore, it is important to perform periodic assessment of hospital infection data and antimicrobial resistance pattern of the pathogens in order to prevent outbreaks and put in place control strategies.

\section{Contributions of the Authors}

TWJM, JCNA, AJ participated in the design of study. TWJM collected and conducted laboratory assay. TWJM and JCNA to data analysis, interpretation and manuscript design. All authors contributed to the review and approved the final version.

\section{Conflicts of Interest}

All the authors do not have any competing interest. 


\section{Acknowledgements}

We thank all the directors and the staff of medical laboratory unit of HJMN, MHD, NBDH and MHCN for their cooperation. We also acknowledge Ako simon, Kenfack Lionel, Meyeme Y. Landry, Tegne john, Asobochia alphonse, Demguia A. Laure and Bessomo E. Ornella for their support. We can't end without thanking the academic staff of Faculty of health Sciences of University of Buea especialy Dr Denis Zofou for his orientation.

\section{References}

[1] Kouchak F, Askarian M. Nosocomial Infections: The Definition Criteria. Iran J Med Sci. 2012; 37 (2): 72-73.

[2] Heaven S, NEWSLETER healthline; What is nosocomial infection, Medically Reviewed by Graham Rogers, MD on 24 octobre 2016. Also Avalable: http: //www.healthline.com/health/medical -board. Accessed on 13 December 2017.

[3] Irene O and Daniel NT. Knowledge and attitude of healthcare workers and patients on healthcare associated infections in a regional hospital in Ghana. Asian Pac J Trop Dis 2014; 4 (2): 135-139.

[4] Murni IK, Duke T, Kinney S, et al. Arch Dis Child Published Online First: 10 December 2014 doi: 10.1136/ archdischild2014-307297.

[5] Sepideh B, Benedetta A, Shamsuzzoha B S, Benjamin E \& Didier P. Health-care-associated infection in Africa: a systematic review Bulletin of the World Health Organization 2011; 89: 757-765.

[6] Nouetchogou NS, Ateudjieu J, Bonaventure J, Edmond NM and Mbanya D. Surveillance of nosocomial infections in the Yaounde University Teaching Hospital, Cameroon. BMC Res Notes (2016) 9: 505.

[7] Barraud D, US National Library of Medicine National Institutes of Health. [Nosocomial infectious: the realities of an endless fight]. Ann Pharm Fr. 2002; 60 (2): 75-87.

[8] Culled from Cameroon Tribune, Posted by PrinceReport at Thursday, September11, 2008.

[9] Emily RM, Sydnor and Trish M. Per. Hospital Epidemiology and Infection Control in Acute-Care Settings. CLIN. MICROBIOL. REV; 2011; 24 (1) p. 141-173.

[10] Sserwadda I, Lukenge M, Mwambi B, Mboowa G, Walusimbi A, Segujja F. Microbial contaminants isolated from items and work surfaces in the post- operative ward at Kawolo general hospital, Uganda. BMC Infect Dis. 06 2018; 18 (1): 68.

[11] Matinyi S, Enoch M, Akia D, Byaruhanga V, Masereka E, Ekeu I, et al. Contamination of microbial pathogens and their antimicrobial pattern in operating theatres of peri-urban eastern Uganda: a cross-sectional study. BMC Infect Dis. 10 sept 2018; 18 (1): 460.

[12] Simon F, Kraemer P, De Pina JJ, Demortière E, Rapp C. Risk of nosocomial infection in intertropical Africa--part 2: patient infection. Med Trop (Mars). 2007; 67 (2): 197-203.

[13] Rebaudet S, Kraemer P, Savini H, De Pina JJ, Rapp C, Demortiere F, Simon F. Risk of nosocomial infection in intertropical Africa--part 3: health care workers. Med Trop (Mars). 2007; 67 (3): 291-300.

[14] World Health Organization. Patient safety. Health careassociated infections Fact SHEET.

[15] World Health Organization. Report on the Burden of Endemic Health Care-Associated Infection Worldwide. 2011.

[16] Simon F, Demortiere E, Chadli M, Kraemer P, De Pina JJ. Risk of noscomial infection in intertropical Africa--part 1: background. Med Trop (Mars). 2006; 66 (1): 91-6.

[17] Cheesbrough M. District laboratory practice in tropical countries. New York: Cambridge University Press; 2006.

[18] Feleke T, Eshetie S, Dagnew M, Endris M, Abebe W, Tiruneh $\mathrm{M}$, et al. Multidrug-resistant bacterial isolates from patients suspected of nosocomial infections at the University of Gondar Comprehensive Specialized Hospital, Northwest Ethiopia. BMC Res Notes. 20 août 2018; 11 (1): 602.

[19] Mama M, Abdissa A, Sewunet T. Antimicrobial susceptibility pattern of bacterial isolates from wound infection and their sensitivity to alternative topical agents at Jimma University Specialized Hospital, South-West Ethiopia. Ann Clin Microbiol Antimicrob. 2014; 13 (1): 1.

[20] Global antimicrobial resistance surveillance system (GLASS) report: early implementation 2017-2018. Geneva: World Health Organization; 2018. Licence: CC BY-NC-SA 3.0 IGO.

[21] Rebaudet S, De Pina JJ, Rapp C, Kraemer P, Savini H, Demortiere $\mathrm{E}$ et al. Risk of nosocomial infection in Intertropical Africa. Part 4: prevention. Med Trop (Mars). 2008 Feb; 68 (1): 73-82.

[22] Weber DJ, Anderson D, Rutala WA. The role of the surface environment in healthcare-associated infections. Curr Opin Infect Dis. 2013 Aug 1; 26 (4): 338-44.

[23] Saxena S, Priyadarshi M, Saxena A, Singh R. Antimicrobial consumption and bacterial resistance pattern in patients admitted in I. C. U at a tertiary care center. J Infect Public Health. oct 2019; 12 (5): 695-9.

[24] Rodrigues S, Conceição T, Silva IS, de Lencastre H, Aires-deSousa M. Frequent MRSA nasal colonization among hospitalized children and their parents in Angola and São Tomé and Príncipe. J Hosp Infect. nov 2018; 100 (3): 344-9.

[25] Bashir A, Garba I, Aliero AA, Kibiya A, Abubakar MH, Ntulume I, et al. Superbugs-related prolonged admissions in three tertiary hospitals, Kano State, Nigeria. Pan Afr Med J. 2019; 32: 166 . 